\title{
Dos tesis historiográficas de la primera mitad del siglo XX en torno al uso de los conceptos de naturaleza y fin en el pensamiento político de Dante Alighieri
}

\author{
Victoria Arroche
}

Universidad de Buenos Aires, Argentina

Recibido el 20/12/2019/Aceptado el 20/02/2020

\section{Resumen}

Este trabajo presenta con bastante detalle y examina críticamente las posturas historiográficas de dos intelectuales que vivieron en la primera mitad del siglo XX: Francesco Ercole (1884-1945) y Bruno Nardi (1884-1968). Estos intelectuales italianos, especialistas en el pensamiento de Dante Alighieri y en particular en su filosofía política, desarrollaron sus respectivos análisis estudiando la articulación entre dos conceptos esenciales en la elaboración de las teorías políticas que surgieron entre el siglo XIII y XIV en el Occidente Latino. En efecto, esas nociones son "naturaleza" y "fin". Uno de los objetivos de este artículo es mostrar que, en el marco de la teoría política presentada por Dante en Monarchia y Convivio, la operatividad de estas ideas resulta fundamental para definir en qué consiste la autonomía de una comunidad respecto de los poderes políticos con los que se relaciona.

Two historiographical theses in the first half of the 2oth century on the use of the concepts of nature and end in Dante Alighieri's political thought

\footnotetext{
Abstract

In this paper I will critically examine the historiographical positions of Francesco Ercole (1884-1945) and Bruno Nardi (1884-1968), two Italian scholars, specialists in Dante's work who lived in the first half of the twentieth century. These intellectuals particularly studied Dante's political philosophy and they inquired about the articulation of "nature" and "end", which are two essential concepts in the elaboration of the political theories in the thirteenth and fourteenth century. This article aims to show that in Dante's political treatises Monarchia and Convivio, the ideas of "nature" and "end" are functional for defining the autonomy of a community with respect to other political powers.
}

Palabras clave

Fin

Naturaleza

Teoría política medieval Dante

Keywords

End

Nature

Medieval Political Theories Dante 
1. Cfr. Dante, Mon, Libro III, 4, 14-15 "remedia contra infirmitatem peccati". Esta sentencia en el Libro III ha dado lugar, junto con otros pasajes, a establecer una cierta incongruencia entre la "naturalidad" del imperio en el Libro Iy su "convencionalidad" en el Libro III.
A pesar de la evidente presencia de elementos neoplatónicos en la obra de Dante, no es menos cierto que los primeros capítulos de Monarchia ofrecen una teoría acerca del fin del imperio y de los fines de las comunidades particulares -i.e. familia, aldea, vecindad, ciudad y reino- que, en efecto, proviene de una corriente de pensamiento conformada a partir del aporte decisivo de los textos aristotélicos que ingresaron al Occidente latino entre los siglos XII y XIII. Justamente, la filosofía aristotélica sostiene la idea de que cada entidad natural posee un fin propio que, al ser alcanzado, constituye su perfección. También, según la argumentación de Dante, el sujeto ético, es decir, la totalidad de la humanidad posee un fin cuya consecución implica su perfección y completitud y, además, el concepto de fin está vinculado, en particular, con una cierta concepción de la naturaleza humana.

Ahora bien, en lo que atañe al análisis de las ideas medievales sobre la naturaleza humana, podríamos mencionar al menos tres categorías historiográficas importantes: la primera, la identificaremos con el pensamiento llamado "aristotélico-tomista" y tendría vinculación con el modo en que Tomás de Aquino concibe la naturaleza de los seres humanos. En efecto, según Aquino, los individuos poseen una esencia vulnerada y despojada de sus dones sobrenaturales pero que, en rigor, se conserva tal como fue creada. Esto es, lo que "cae" con el pecado original, no es la naturaleza humana tal como fue creada por Dios sino que ella pierde los dones añadidos y, por lo tanto, sobrenaturales (Tomás de Aquino, S.Th. I, q. 96, a.4).

Por otra parte, en el marco de la historiografía sobre el pensamiento político medieval, para explicar el orden político y social entre los seres humanos resultó útil una categoría denominada "agustinismo político" (Arquillière, 1934; Bertelloni, 2011: 14-15), que implica una cierta interpretación de algunos textos de Agustín, según la cual la naturaleza humana debería ser restaurada o auxiliada a través de la gracia que constituye, precisamente, un verdadero remedium peccati. ${ }^{1}$

Además de estas dos posturas, otros historiadores de la filosofía se abocaron al estudio de corrientes de pensamiento, quizás menos conocidas, que dieron lugar a nuevas categorías historiográficas como el llamado averroísmo latino o, más recientemente, aristotelismo radical o heterodoxo (Van Steenberghen, 1980; De Libera, 1991; Bianchi, 1994; Imbach, 2003; Minecan, 2010) que, a su vez, permitieron clasificar algunas ideas de pensadores medievales -tales como Siger de Brabante, Boecio de Dacia y el mismo Dante- dentro del denominado "averroísmo político" (Nardi, 1967: 256; Bertelloni, 2012).

Durante la primera mitad del siglo XX, Francesco Ercole (1884-1945) y Bruno Nardi (1884-1968) realizaron importantes aportes teóricos relativos a la noción de fin pues estudiaron el problema en torno a si Dante consideró la monarquía como una institución natural o sobrenatural. En efecto, de acuerdo con la filosofía aristotélica, la idea de finalidad vinculada conceptualmente con la noción de naturaleza, implicaría que, en el primer caso, -i.e. si la monarquía fuera una institución natural- entonces su fin, que constituye la entelequia o perfección de la sociedad humana, sería alcanzable en esta vida sin ayuda ab extra. Ello indicaría, asimismo, que el imperio posee una cierta autonomía respecto de la iglesia. En cambio, si se considera válido el marco teórico planteado por el "agustinismo político" para analizar la naturaleza o sobre-naturaleza de la monarquía en el tratado de Dante, entonces el imperio se presentaría como una institución fundada directamente por Dios como consecuencia del pecado original, que afectó a la totalidad de la humanidad y, al mismo tiempo, como remedio contra ese pecado. El fin del imperio, por lo tanto, quedaría subordinado a un fin superior, en la vida futura, al cual puede llegarse a través de ciertos poderes administrados por la iglesia -como el bautismo- que constituyen la condición de posibilidad para alcanzar ese fin último. 
En relación con el llamado "averroísmo político" considero que no es una categoría que pueda dar cuenta cabalmente de los matices que presenta el pensamiento político y filosófico de Dante aunque es posible encontrar en él algunos de los elementos que caracterizan al movimiento intelectual llamado "averroísmo latino".

Como ha mostrado Francisco Bertelloni (2004a; 2004b; 2009), el tratamiento acerca de la finalidad de cada comunidad particular y la subordinación de algunos fines respecto de otros, también determinan el grado de autonomía que adquieren las distintas instituciones. Precisamente, uno de los problemas que examina Dante en su tratado Monarchia es la autonomía del imperio frente a la iglesia. Por eso, aportar una definición al problema de la naturaleza o sobre-naturaleza de la monarquía como institución política, implica determinar el alcance que tiene la justificación conceptual de Dante al sostener la autonomía del gobierno temporal frente al espiritual. Sobre ese punto, durante el siglo XX, dos historiadores de la filosofía medieval y especialistas en el pensamiento de Dante expusieron sus ideas elaborando dos tesis contrapuestas acerca del origen del imperio vinculado con la forma de comprender la naturaleza humana y, por lo tanto, propusieron dos modos distintos de pensar el concepto de finalidad.

\section{La posición aristotélico-tomista de Ercole y el carácter sobre- natural del Imperio}

Francesco Ercole publicó su libro, Il pensiero politico di Dante, en 1928. El texto es, claramente, un escrito sobre teoría política. La característica más destacable, en ese sentido, es la búsqueda por parte del autor de los fundamentos filosóficos y jurídicos del pensamiento político de Dante, principalmente en Convivio y Monarchia.

En lo que atañe a su punto de vista historiográfico nos resulta de mucho interés marcar el contrapunto de su propuesta respecto de la de Bruno Nardi quien rechazó, en varios de sus artículos y libros (Nardi, 1912; 1938; 1944; 1949; 1967), la tesis compartida por algunos estudiosos del pensamiento de Dante según la cual este debe ser leído e investigado en el marco general de la filosofía tomista (Mandonnet, 1911; 1935; Busnelli, 1921). En ese debate se inserta Ercole proponiendo, por el contrario, que la filosofía "aristotélico-tomista" es la base de la idea dantesca de la "sociedad humana" (umana civiltá) (Ercole, 1928: 39-131).

La polémica entre Ercole y Nardi se desarrolla en torno a uno de los argumentos principales del Libro I de la Monarchia. En efecto, se trata del pasaje en el cual Dante establece, en primer lugar, una comparación entre, por un lado, las partes orgánicas que componen el cuerpo y, por el otro, las comunidades particulares que constituyen las partes de la humana civilitas, ${ }^{2}$ en segundo término, Dante señala que así como cada parte orgánica posee un fin propio y distinto de los demás, también lo tiene cada comunidad particular. En tercer lugar, nuestro autor indica que el fin de la humana civilitas es último respecto de los fines precedentes y constituye, en ese sentido, el principio a partir del cual pueden deducirse los argumentos verdaderos que conforman la investigación dantesca. ${ }^{3} \mathrm{El}$ pasaje dice:

Veamos ahora cuál es el fin de toda la sociedad humana. Y para esclarecer aquello que buscamos advirtamos que del mismo modo como la naturaleza determina el pulgar a un determinado fin, a otro fin toda la mano, a otro el brazo y finalmente a un fin distinto de todos ellos a todo el hombre, así también uno es el fin al que la naturaleza determina el individuo, otro el fin al que determina la comunidad doméstica, así otro será el fin de los que viven en vecindad, otro el de quienes lo hacen en la ciudad, otro el del reino y otro, superior a todos los otros, aquel
2. Dante refiere a la totalidad de la humanidad con esta fórmula "sociedad humana". Para el término civilitas Cfr. Minio-Paluello, 1955.

3. Los capítulos 3 y 4 del Libro I de Monarchia fueron comentados y criticados tanto por autores medievales como por autores contemporáneos porque exponen uno de los puntos más polémicos del tratado ya que, en virtud de la cita a Averroes con la que Dante justifica teóricamente sus ideas, nuestro autor fue calificado como averroísta y acusado de sostener una doctrina herética: la unicidad y la separación del intelecto posible. En efecto, uno de los primeros críticos de Dante fue el fraile Guido Vernani (1290-1345). Ni Francesco Ercole ni Bruno Nardi consideran que Dante haya aceptado la tesis averroísta del intelecto único y separado. Cfr. Ercole, 1928:149 y Nardi, 1967: 238-239. 
4. “Nunc autem videndum est quid sit finis totius humane civilitatis [...] Et ad evidentiam eius quod queritur advertendum quod, quemadmodum est finis aliquis ad quem natura producit pollicem et alius ab hoc ad quem manum totam et rursus alius $a b$ utroque ad quem brachium aliusque b omnibus ad quem totum hominem; sic alius est finis ad quem singularem hominem, alius ad quem ordinat domesticam comunitatem, alius ad quem viciniam, et alius ad quem civitatem, et alius ad quem regnum, et denique ultimus ad quem universaliter genus humanum Deus eternus arte sua, qua natura est, in esse producit. Et hoc queritur hic tanquam principium inquisitionis directivum" (Dante, Mon. I, 3,

1-3). Todas las traducciones al castellano de los fragmentos en latín e italiano a lo largo del artículo son de mi autoría.

5. "Ora la enumerazione e descrizione che in Dante si incontra di queste communitates naturalmente necessarie, e costituenti quindi la naturale ossatura della umana civiltà, è di pretta derivazione aristotélico-tomistica, come del resto, da Aristotele e da San Tommaso ne deriva il concetto informatore [...] La città e il regno non presupongono al di sopra di sè naturalmente alcun'altra maggiore communitas integratrice: appunto perchè il loro fine naturale è proprio la sufficientia [...] Chè, se alcuno opponesse essere per Dante non meno necessaria alla vita felice degli uomini la monarchia universale, non ho per ora da osservare se non che la monarchia universale, se è certo per Dante necessaria, non è però affatto naturalmente necessaria. Essa è invero il remedio ordinato direttamente da Dio, con la Chiesa, contro le consecuenze di un fatto non naturale, quale fu ed è il peccato. Se non ci fosse il peccato, la monarchia universale non sarebbe mai stata necessaria" (Ercole 1928: 78-80, n.1). Cursiva en el original. en virtud del cual Dios eterno, por medio de su arte que es la naturaleza, creó todo el género humano. Es precisamente este fin el que buscamos como principio rector de nuestra investigación (Dante, Mon. I, 3, 1-3).4

En su obra Ilpensiero politico di Dante, Ercole afirma que los fines de las comunidades particulares son naturales mientras que el fin de la monarquía o imperio no lo es:

La enumeración y descripción que encontramos en el texto de Dante de estas comunitatesnaturalmente necesarias, y que constituyen, por lo tanto, el esqueleto natural de la sociedad humana (umana civiltà), deriva estrictamente de la doctrina aristotélico-tomista [...]. La ciudad y el reino no presuponen, por encima de ellas, de manera natural, ninguna otra comunidad mayor que las integre porque, justamente, su fin propio natural es la sufficientia [...]. Y, si alguno argumentase que, para Dante, la monarquía universal no es menos necesaria (que las comunidades) para la vida feliz de los hombres, hago notar que si bien es cierto que, para Dante, la monarquía universal es necesaria, de ninguna manera es naturalmente necesaria. Ésta es, en verdad, el remedio ordenado directamente por Dios, junto con la Iglesia, contra las consecuencias de un hecho no natural, tal como fue y es el pecado. Si no existiese el pecado, la monarquía universal no hubiese sido jamás necesaria (Ercole, 1928: 78-80, n.1). ${ }^{5}$

La fórmula umana civiltà, que traducimos como "sociedad humana" es definida por Ercole como una idea aristotélico-tomista. En ese sentido la entiende el historiador cuando explica que la sociabilidad es una necesidad natural de los hombres y que esta idea se presenta a Dante como evidente porque la adopta directamente de Aristóteles y de Tomás de Aquino (Ercole, 1928:43). Me concentraré, entonces, en la caracterización de las comunidades particulares como "naturales" en contraposición con el imperio o monarquía que es definida, por Ercole, como una institución sobrenatural.

La sociedad humana, según la argumentación de Ercole, se constituye a partir de la existencia de una serie de comunidades menores respecto del imperio. A ello parece referirse el autor cuando explica que esas comunidades son necesarias pues constituyen el esqueleto natural de la umana civiltà. El carácter natural de las comunidades particulares tiene relación con que sus fines no devienen de un hecho sobrenatural y, por ello, son alcanzables sin la ayuda ni la intervención de elementos que se encuentren por fuera de las capacidades específicas de esas comunidades. Por ello, Ercole señala que el fin de la ciudad o del reino es la sufficientia. Con este término, el historiador subraya la capacidad de esas comunidades para alcanzar su fin propio sin la intervención divina o de la iglesia. El hecho de que una comunidad alcance su fin naturalmente, que se baste o sea suficiente para lograr su consecución, le otorgaría autonomía pues su perfección como comunidad no depende de otro sino de sí misma. El análisis que Ercole propone en el capítulo II de su libro sostiene que las comunidades particulares constituyen el esqueleto de la sociabilidad humana y puesto que el individuo busca naturalmente vivir en sociedad y conforma naturalmente esas comunidades particulares también es natural la sociabilidad humana. Al mismo tiempo, puesto que las comunidades particulares poseen un fin propio que constituye su perfección, en lo que atañe a esas comunidades y a la umana civiltá, naturalidad y necesidad se identifican. Según Ercole, este tipo de naturalismo se correspondería con la idea de naturaleza presente en los textos aristotélicos que ingresaron en el siglo XIII al occidente latino.

No sucede lo mismo respecto de la monarquía. Esta institución no es natural porque fue establecida, exclusivamente, en virtud de la existencia de un hecho sobrenatural: el pecado. Como remedio contra esa enfermedad, ella fue creada directamente por Dios. En virtud de la herencia que la humanidad recibe de los primeros padres, el 
imperio resulta necesario para su redención; pero puesto que su justificación obedece a un hecho sobrenatural, el imperio o monarquía no es naturalmente necesaria. Según su lectura, Ercole plantea que la sociedad humana posee ciertos fines que alcanza de acuerdo a su pertenencia a una determinada comunidad. Precisamente, la familia posee un fin distinto al de la aldea y esta posee otro fin diverso al de la ciudad y cada uno de ellos se establece según las necesidades de cada comunidad. Por eso, esas comunidades particulares constituyen la condición de posibilidad para que cada parte de la humanidad pueda alcanzar ciertos fines proporcionales a cada una de esas comunidades. La justificación teórica de este esquema propuesto por Ercole se fundamenta, precisamente, en la sociabilidad natural del hombre. El concepto de sufficientia, establecido en relación a esos fines, caracteriza a las comunidades particulares que, en ese sentido, deberían poder evitar la intervención eclesiástica en aquello que atañe, por ejemplo, a la resolución de un conflicto.

En cambio, el caso de la totalidad de la sociedad humana que es dirigida hacia su fin por el monarca resulta diverso pues ella no puede alcanzar su fin propio, la vida feliz, por sí misma. En ese sentido y según esta interpretación, Dante postularía que la consecución del fin propio de la humanidad exige la existencia de una institución que ejerza un freno sobre la humanidad apartándola del pecado. El imperio cumple esa función, limitar la avaricia, proveniente del pecado original, que afecta a toda la humanidad, ordenándola hacia su fin propio, a saber, la felicidad. ${ }^{6}$ Sin embargo, también según esta formulación, la totalidad de la humanidad debería resignar su autonomía frente al poder espiritual como consecuencia del pecado (Ercole, 1928:136-142).

En el capítulo III del Pensiero politico di Dante, Ercole retoma lo dicho en el capítulo II. En efecto, la sufficientia de cualquier comunidad radica en la capacidad de alcanzar su perfección por sí misma. Según el historiador, para Dante el ejemplo de una comunidad autárquica es cualquier nación de hombres unidos por la costumbre, el origen histórico, la lengua (Ercole, 1928:135). Estos caracteres conforman aquello que Dante denominaría civilitas. Cuando una comunidad civil excede los límites de una ciudad, esta se une a otras en virtud de una tendencia natural, conformando un organismo político mayor denominado reino. De este modo "se sigue que la umana civiltà resulta naturalmente del conjunto de todas las communitates perfectae et per se sufficientes, que componen la humana universitas" (Ercole, 1928:136). ${ }^{7}$

El análisis sobre el concepto de fin que presenta Ercole comienza por el Libro III de la Monarchia. Allí, en efecto, Dante establece que el fin del hombre consiste en la vida feliz. La idea de beatitudo es presentada en el marco de la distinción entre dos tipos de felicidades. Según lo expuesto en Monarchia, una de ellas se obtiene en esta vida y la otra en la vida futura y cada una se corresponde con dos fines. ${ }^{8}$ Es manifiesto, por tanto, que en el tratado Monarchia las dos beatitudes implican un duplexfinis. Ahora bien, como explica Ercole, Dante establece que la beatitudo huius vitae (fin) consiste en la operatio propriae virtutis "que es lo mismo que decir, en la capacidad que está naturalmente ínsita en el hombre en cuanto hombre (Mon. III, 15, 7)" y, dice también, que esa capacidad es la potentia sive virtus intellectiva (Ercole, 1928: 46-47). Por ello, según nuestra lectura, estas premisas están en relación con lo expuesto por Dante en el Libro I de la Monarchia, a saber, que el fin de la totalidad de la humanidad es la actualización del intelecto posible total y simultáneamente. Es decir, el ejercicio actual de la virtus intellectiva por parte de una totalidad, al mismo tiempo y siempre. En este sentido, llama la atención que al analizar el fin de la humana universitas, Ercole no mencione esa argumentación sino que recurra a la exposición del libro IV, capítulo 4 de Convivio. En efecto, dice Ercole:

El hombre que está destinado naturalmente a la felicidad en la tierra, es naturalmente incapaz o insuficiente para alcanzarla individualmente: es decir,
6. Ejemplos que apoyen esta lectura en Monarchia, Libro III, 4, 14 (fórmula ratione peccat); Libro III, 15, 10 (in camo et freno); Convivio, IV, 9, 10 (el emperador es el "cavalcatore dell'umana volontade").

7. "Ne segue che la umana civiltá risulta naturalmente dall'insieme di tutte le communitates perfectae et per se sufficientes, di cui l'humana universitas è composta" (Ercole, 1928:136). Cursiva en el original. De esa forma, aquello que Ercole define como sociedad humana (umana civiltá) en esta argumentación, no debería identificarse con aquello que Dante define como la totalidad de la humana civilitas o humanus genus. Podría inferirse del análisis de Ercole, que la umana civiltà constituye una parte de la humana universitas pues mientras que a la primera la define como conformada por las comunidades particulares $y$, justamente en ello radica su naturalidad, la segunda correspondería a la descripción de la totalidad sujeta a una monarquía cuyo origen es, según señala Ercole, sobrenatural.

8. En Conv. IV, 17, 9, Dante establece la existencia de dos felicidades alcanzables por el ser humano en esta vida: la felicidad de la vida práctica y la felicidad de la vida especulativa. En rigor, se trata de tres felicidades (cfr. Ercole, 1928:48-49). En Monarchia III, 16, en cambio, las dos felicidades se plantean en relación con esta vida (huius vite) y la vida futura (vite aecterne). En ese sentido, el análisis que presenta Ercole propone equiparar el planteo de Convivio y Monarchia pues el autor interpreta el doble fin de este último tratado como fin de la vida práctica y fin de la vida especulativa. 
9. "L'uomo, che è naturalmente destinato alla beatitudine sulla terra, è naturalmente incapace o insufficiente a conseguirla da solo: non può, cioè, da solo, nè operare la virtù nella vita attiva, nè conoscere [...] la veritánella vita speculativa." (Ercole, 1928:56-57). Cursiva en el original.

10. "Lo fondamento radicale de la imperiale maiestade, secondo lo vero, è la necessità de la umana civilitade, che a uno fine è ordinata, cioè a vita felice; a la quale nullo per sè è sufficiente a venire senza l'aiutorio d'alcuno, con ciò sia cosa che l'uomo abbisogna di molte cose, a le quali uno solo satisfare non può. E però dice lo Filosofo che l'uomo naturalmente è compagnevole animale" (Dante, Conv. IV, 4, 1-2).

11. El pasaje continúa con la descripción de las comunidades menores mostrando que cada una no satisface sus necesidades porque se agranda en tamaño y cantidad. En virtud de esa necesidad se pasa de una aldea, por ejemplo, a una ciudad. El aumento, en este caso, es cuantitativo, no hay distinción de fines (de hecho Dante no distingue aquí fines propios de cada comunidad como lo hace en Monarchia), no es mejor el fin del imperio que el de la ciudad sino que se define por un criterio numérico pues la comunidad abarca más personas y satisface más necesidades. En este contexto, como se desprende del argumento en cuestión, el monarca es aquel que limita el afán de crecimiento, justamente el monarca es quien debe frenar la ambición de cosas que satisfacen necesidades, la cupidigia que requiere siempre un aumento cuantitativo de bienes, tierras, etc. (Cfr. Conv. IV, 4, 2-4).

12. Es decir, las necesidades básicas para la vida refieren a aquello que los animales resuelven naturalmente como el calor, el frío, el alimento y la defensa de la vida.

13. "Se Dio ha creato gli uomini per la felicità, anche sulla terra, e ha voluto che la felicità terrena consista nell' uso prudente, cioè virtuoso dell'intelletto, come avviene che ciascun uomo sia, per legge di natura [...] insufficiente a conseguire quello che è il suo fine naturale, senza il quale la vita umana è un tendere senza possa a un bene inafferrabile? La spiegazione di questo contrasto è chiaramente sentita da Dante, e si riconnette ai principii fondamentali della metafísica e della psicologia dantesca, quali Dante apprende, più o meno fedelmente, alla tradizione aristotélico-tomista" (Ercole, 1928:57). Cursiva en el original. no puede, solo, ni poner en práctica la virtud en la vida activa, ni conocer [...] la verdad en la vida especulativa (Ercole, 1928:56-57). ${ }^{9}$

El recurso al tratado IV del Convivio resulta notable porque la argumentación allí ofrecida no parece ser del mismo tipo que la especulación del Libro I de Monarchia. En efecto, como señala Ercole, en Convivio Dante sostiene sus juicios acerca de la sociabilidad natural del hombre destacando como punto central del argumento la satisfacción de ciertas necesidades básicas para la vida suficiente. Justamente, el argumento de Convivio IV, 4 que cita Ercole dice:

El fundamento radical de la majestad imperial, de acuerdo con la verdad, es la necesidad de la civilización humana, que está ordenada a un fin, esto es, a la vida feliz, la cual nadie puede alcanzar por sí solo sin la ayuda de algún otro, pues el hombre tiene necesidad de muchas cosas que uno solo no puede satisfacer. Por eso, el Filósofo dice que el hombre es un animal sociable (Dante, Conv. IV, 4, 1-2). ${ }^{10}$

Como subraya el historiador, las comunidades menores pueden concebirse como naturales en función de la sufficientia que las caracteriza, esto es, en virtud de que su institución responde a un fin natural determinado y no es producto de un evento sobrenatural como el pecado. Sin embargo, en este pasaje del Convivio, Dante destaca la insuficiencia de la umana civilitade para alcanzar su fin. Lo hace mediante la idea de necesidad puntualizando el hecho de que no puede ser satisfecha por uno solo sino que requiere la participación de muchos o de todos. Ahora bien, en Convivio, Dante postula como fin de la umana civilitade la vita felice y aún no especifica en qué consiste esa felicidad. Así, de este pasaje solo podemos deducir, en primer lugar, que el individuo en soledad y por sí mismo es insuficiente para alcanzar su fin y, en segundo lugar, que esa insuficiencia refiere a la imposibilidad de satisfacer ciertas necesidades vinculadas a la supervivencia. ${ }^{11}$

En cambio, en el tratado Monarchia, Dante no describe al fin de la totalidad de la humanidad como la felicidad en general sino que postula la existencia de una operación específica, la actualización del intelecto posible, que constituye la perfección de la potencia última del hombre, a saber, su virtus intellectiva. No se trata, entonces, de una satisfacción de necesidades para la suficiencia de vida, ${ }^{12}$ sino de la perfección natural de los seres humanos que cada uno, como individuo, solo puede alcanzar en cuanto ciudadano (cive) o miembro de una sociedad.

De hecho, a partir de su propio análisis, Ercole encuentra una "aparente contradicción" en la argumentación dantesca:

Si Dios ha creado a los hombres para la felicidad, también en la tierra, y quiso que la felicidad terrena consista en el uso virtuoso del intelecto, ¿cómo se explica que cada hombre sea, por la ley de la naturaleza [...] insuficiente para alcanzar aquello que es su fin natural, sin el cual la vida humana sería un tender continuo hacia un bien inalcanzable? La explicación de este contraste es claramente sentida por Dante aunque [él] no la exprese explícitamente y se conecta con los principios fundamentales de la metafísica y la psicología dantesca, que Dante toma, más o menos fielmente, de la tradición aristotélico-tomista (Ercole, 1928:57). ${ }^{13}$

La explicación del contraste entre una tendencia natural hacia un fin propio y la insuficiencia natural para alcanzarlo radica, según Ercole, en los aspectos metafísicos y psicológicos de la argumentación de Dante que siguen, de modo más o menos fiel, la doctrina aristotélico-tomista. La expresión "más o menos" podría dar cuenta de la dificultad para identificar las fuentes filosóficas de la Monarchia y para clasificar esa obra tratando de que encaje en una única tradición de pensamiento. 
En el apartado III del capítulo III titulado "Lautarchia del fine terreno dellruomo o della "umana civiltà" e un apparente spunto averroistico nel pensiero di Dante", Ercole analiza el concepto de "fin de la totalidad de la humanidad" que Dante enuncia en Monarchia I, 3.

La concepción sobrenatural del imperio, según Ercole, no contradice "como podría parecer a primera vista" los primeros capítulos del Libro I de Monarchia (Ercole, 1928:147). En efecto, en el capítulo III de su obra, Ercole parece replantear el modo en que podría interpretarse el concepto de finalidad en el tratado político de Dante:

En realidad y sin duda, hay algo, en el primer libro de la Monarchia que no aparece en el Convivio ni en la Comedia, ni en otras obras de Dante y es el esfuerzo con el que Dante logra afirmar, sobre bases filosóficas, en parte originales frente al tomismo [...] la autonomía del fin terreno del hombre (Ercole, 1928:147-148). ${ }^{14}$

\section{La posición agustiniana según Nardi y el carácter sobre-natural de las comunidades particulares y del Imperio}

El debate sobre el supuesto tomismo de Dante tuvo lugar en la primera mitad del siglo XX. Por ello, Karl Ubl lo adjudica a un contexto histórico-político particular en el que se pretendió establecer una concordancia entre el nacionalismo y el catolicismo, conciliando las opiniones críticas de Dante sobre la iglesia con su rol como poeta nacional (Ubl, 2003). En ese contexto, rechazando la caracterización tomista de su pensamiento, Bruno Nardi insistió no solo en su naturaleza no ortodoxa, sino también en la necesidad de ampliar la visión interpretativa sobre el problema de las fuentes de la filosofía dantesca.

Específicamente, respecto del estudio del pensamiento político del Alighieri, Nardi manifiesta algunos de los puntos en los que disiente con el análisis expuesto por Ercole en dos artículos. Uno de ellos se titula "Il concetto dell'Impero nello svolgimento del pensiero dantesco" y otro "Le tre pretese fasi del pensiero politico di Dante" (Nardi, 1967: 276-310). A este segundo artículo lo elabora en clara contraposición al capítulo VI del libro de Ercole titulado "Le tre fasi del pensiero politico di Dante". En relación con esos estudios realizados por Nardi analizaremos particularmente uno de ellos " Il concetto dell'Impero nello svolgimento del pensiero dantesco" (Nardi, 1967:215-275) para marcar el contrapunto de su interpretación con la de Ercole.

Constituye uno de los méritos de Nardi haber llamado la atención sobre la multiplicidad de fuentes a las que recurre Dante y marcar, de esa forma, la distancia que lo separa de la doctrina aristotélica tal como es presentada por Tomás de Aquino. Así, uno de los elementos que Nardi rescata de la tesis de Ercole es que existe una oposición entre el pensamiento patrístico y el tomista en el modo de concebir la naturaleza humana y, por ende, el concepto de Estado:

El modo diverso en el que se entiende la naturalidad y racionalidad del Estado, en la patrística y en el tomismo, se funda sobre el modo diverso de concebir la naturaleza humana en sí [...] por ahora, basta haber establecido la verdad que existe en la oposición, afirmada por Ercole y puesta en duda por Parodi, entre el pensamiento patrístico y el tomista, en torno al concepto de Estado (Nardi, 1967:224-225). ${ }^{15}$

En ese sentido, Nardi considera que la nueva idea de naturaleza adoptada a partir del ingreso de Aristóteles en el occidente latino es la que Tomás de Aquino utiliza para elaborar su doctrina acerca del Estado (Nardi, 1967:222-223). En cambio, la
14. "C'è, in realtà, e senza dubbio, nel primo libro della Monarchia qualcosa che non c'è nè nel Convivio, nè nel Poema, nè in altre opere di Dante: ed è lo sforzo, con cui Dante riesce ad affermare, su basi filosofiche, in parte originali di fronte allo stesso tomismo [...] la autonomia del fine terreno dell'uomo" (Ercole, 1928:147-148).
15. “Il modo diverso d'intendere la naturalità e razionalità dello Stato, nella Patristica e nel tomismo, si fonda sul diverso modo di concepire la natura umana in sè $[. .$.$] per ora ci basti avere$ stabilito in che consista il nocciolo di verit che è nell'oposizione, assertita dall'Ercole e messa in dubio dal Parodi, fra il pensiero patrístico e quello tomístico, intorno al concetto di Stato" (Nardi, 1967: 224-225). 
16. “Ma è evidente che, pur accogliendo il procedimento dimostrativo della politica aristotelica, egli [Dante] ha sempre dinanzi agli occhi della mente il concetto di una natura umana intrinsecamente viziata e diminuita [...] necessario, e quindi naturale, è all'uomo che "fosse cive", e "rege avere"; ma tale necessità é [...] risultante dell'intrinseca corruzione attuale della natura umana [...] In questo senso va intesa appunto la naturalità dello Stato secondo Dante, e non nel senso aristotelico-tomista. Per lui, il "regimen temporale" in genere, cioè qualunque forma di Stato, e non il solo Impero, è reso necessario dall'imperfezione della natura umana, ed è un remedio 'contra infirmitatem peccati'" (Nardi, 1967:227-228). idea de una naturaleza humana intrínsecamente corrupta, que deriva de la doctrina agustiniana es la que inspira a Dante para elaborar la teoría política expuesta en su tratado Monarchia (Nardi, 1967: 223-226). De esto se sigue, en el análisis de Nardi que, a pesar de que para Dante el Estado no es una institución natural, la demostración de esa no naturalidad no sería de inspiración agustiniana sino aristotélica. Dicho de otro modo: el contenido es agustiniano pero la forma es aristotélica.

Pero es evidente que, aún en el marco del procedimiento demostrativo de la política aristotélica, él (Dante) siempre tiene delante de los ojos de la mente el concepto de una naturaleza intrínsecamente viciada y disminuida [...] necesario y por lo tanto natural resulta para el hombre ser ciudadano o tener un rey; pero tal necesidad es [...] el resultado de la intrínseca corrupción actual de la naturaleza humana [...]. En este sentido tiene que ser comprendida la naturalidad del Estado según Dante y no en el sentido aristotélico-tomista. Para él, el "régimen temporal" en general, es decir, cualquier forma de Estado y no solo el Imperio, se torna necesario a partir de la imperfección de la naturaleza humana y es un remedio 'contra infirmitatem peccati' (Nardi, 1967:227-228). ${ }^{16}$

En efecto, según Nardi, no sólo el imperio es concebido por Dante como una institución sobrenatural por su origen -el pecado- y por su función -el remedio contra ese pecado- sino también el "régimen temporal en general", es decir, "cualquier forma de Estado". De allí que, según esta lectura, sea posible interpretar que todas las comunidades particulares responden al mismo origen y se constituyen como parte del plan providencial divino para la salvación de la humanidad. Ahora bien, de este trabajo nos interesa destacar la noción de naturaleza que propone Nardi pues, verdaderamente, ella parece designar un modo intrínseco originalmente corrupto de la condición humana. En efecto, el imperio oficia de remedio contra la consecuencia del pecado, a saber, una naturaleza humana caída e imperfecta. Sin embargo, según el pasaje de Nardi, la naturalidad del Estado resulta coincidente con su origen pecaminoso, es decir, con un evento sobrenatural. Dicho con otras palabras, la propuesta de Nardi no parece plantear una oposición conceptual entre las nociones natural y sobrenatural sino más bien comprender la naturalidad del ser humano y de sus instituciones políticas como productos de un hecho sobrenatural -el pecado- y que, quizás paradójicamente, constituye la naturaleza/esencia de la humanidad y de sus instituciones. Ahora bien, esta interpretación genera un problema conceptual con relación a la teoría política dantesca en el Libro I pues, si el fin al que tiende la humanidad -sea natural o sobrenatural- debe alcanzarse necesariamente porque la naturaleza no hace nada en vano, ¿por qué la humanidad estaría incapacitada para alcanzar ese fin y en qué sentido el imperio constituiría un remedio contra el pecado cuando, en rigor, se trataría de una institución fundada sobre la base de un hecho sobrenatural? Es decir, según la lectura de Nardi podría ponerse en duda la necesidad del imperio y del monarca para la consecución del bien del mundo, cuestión que Dante se ocupa de afirmar en la argumentación de todo el Libro I. Dicho de otro modo, ¿por qué sería necesaria la monarquía si en realidad el papa resultaría suficiente para remediar el pecado que, según esta lectura, es el evento sobrenatural que da origen a lo político?

\section{Conclusión}

Tanto Ercole como Nardi postulan que el planteo político de Dante tiene como trasfondo teórico y doctrinal una determinada metafísica que implica una posición ontológica, antropológica y gnoseológica. En el caso de Ercole, la naturalidad de los fines de las comunidades particulares se construye sobre la llamada "doctrina 
aristotélico-tomista". Por ello, mientras que las comunidades particulares resultan "aristotélicamente" suficientes, la monarquía queda excluida del ámbito de la naturaleza. Esta doctrina resulta insuficiente a la hora de explicar el modo en el que se relacionan, conceptualmente, la totalidad de la humanidad y el monarca puesto que éste es la guía de esa totalidad hacia su fin propio, que se define como alcanzable en esta vida. En efecto, considero que la base aristotélico/tomista dificulta la interpretación de los numerosos pasajes en los que Dante estima que la monarquía es necesaria porque constituye la condición de posibilidad para que la humanidad alcance su fin último y ejerza su operación específica en el ámbito temporal y contingente. Asimismo, esta concepción del fin de la monarquía como sobrenatural genera la paradoja de que la institución que debe conducir a todas las comunidades particulares hacia su fin -v.g. el imperio- de acuerdo con la insuficiencia que la caracteriza, debe subordinarse al fin superior del papado. En cambio, las comunidades menores que se ordenan al fin de la monarquía, se manifiestan autónomas para alcanzar su fin propio y, en ese sentido, cumplen con un requisito que la institución a la que se ordenan no tiene, a saber, la sufficientia.

En el caso de Nardi, hemos señalado la dificultad que comporta no solo considerar al imperio sino también a todo tipo de formación comunitaria de carácter temporal como el resultado de un hecho sobrenatural como es el pecado. Precisamente, esta interpretación supone la teoría antropológica agustiniana según la cual la naturaleza humana se revela imperfecta para alcanzar su fin y ello conduciría a postular una entidad natural creada con un fin que, sin embargo, no podrá alcanzar nunca por su propia potencia.

En suma, en el argumento que ambos historiadores toman como punto de partida de su propio análisis, Dante establece una comparación entre, por un lado, los fines propios de cada parte del cuerpo humano y del hombre como totalidad y, por el otro, entre las comunidades particulares y la monarquía, que comprende a todo el género humano. Según nuestra lectura, el criterio por el cual un régimen de gobierno puede definirse como mejor, pues su fin es superior al de las demás comunidades, es el que fundamenta metafísicamente la existencia de los fines inferiores y de las comunidades particulares. Dicho de otro modo: la monarquía (totalidad/unidad) no deviene de una suma de comunidades menores (partes/multiplicidad); por el contrario, ella garantiza su existencia. En efecto, como explica Dante, el fin de la totalidad de la humanidad constituye una entelequia y, asimismo, es la causa de la existencia de los fines a los que se ordenan las comunidades particulares. Por eso, se trata de un principio metafísico, explícitamente establecido por Dante y vinculado con la noción de finalidad:

Puesto que en el orden del obrar todo principio y causa es el fin último que mueve al agente en su acción, consecuentemente la razón de todas las acciones que están ordenadas a un fin debe poder deducirse de ese mismo fin (Dante, Mon. I, $2,7-8) .{ }^{17}$

A pesar, entonces, de que Francesco Ercole y Bruno Nardi no compartieron la misma idea acerca de la justificación teórica de la existencia del imperio enunciada por Dante, ambas posturas manifiestan una característica común: la intención de que el tratado Monarchia sea analizado teniendo en cuenta un único modelo filosófico. Esta modalidad comporta algunas dificultades: por un lado, sobre la base de la doctrina aristotélico-tomista, el obstáculo reside en poder explicar la idea, presente en el texto de Dante, acerca de la existencia de un fin último natural, esto es, alcanzable en esta vida mediante una operación específica que puede ejecutar el conjunto de la sociedad. Por otro lado, sobre la base de la doctrina agustiniana, relativa a la condición imperfecta de la naturaleza humana, se debe acudir a una
17. "Cum in operabilibus principium et causa omnium sit ultimus finis, movet enim primo agentem, consequens est ut omnis ratio eorum que sunt ad finem ab ipso fine sumatur" (Dante, Mon. I, 2, 7-8). 
18. Sobre el vínculo conceptual entre "temporal" y "natural", valga la convincente explicación de Vinay (1962: 9, n. 3): "tempus" hace referencia al mundo de las "corruptibilia" y al "regnum nostre mortalitatis". identificación de lo natural y lo sobrenatural anulando, por ejemplo, la definición explícita que Dante ofrece del imperio al destacar su carácter temporal y superior a toda autoridad constituida en ese ámbito contingente. ${ }^{18}$ En ese sentido, según nuestra interpretación, el apremio por catalogar el pensamiento de Dante de acuerdo con una única tradición filosófica, resulta un escollo para la comprensión del tratado político. 


\section{Bibliografía}

"Arquillière, H-X. (1934). L'Agustinisme politique, Essai sur la formation des théories politiques au Moyen Age. Paris: Vrin.

"Bertelloni, F. (2004). Filosofía y Teoría Política en la Edad Media (modelos causales en las teorías políticas de Tomás de Aquino y Egidio Romano). Anales de Estudios Clásicos y Medievales, vol. 1,61-90.

"Bertelloni, F. (2004). Sobre las fuentes de la Bula Unam Sanctam (Bonifacio VIII y el De Ecclesiastica Protestate de Egidio Romano). Pensiero Politico Medievale II, 89-122.

" Bertelloni, F. (2009), Algunas interpretaciones de la causalidad final aristotélica en la teoría política medieval. En Filippi, S. (Ed.), Cuestiones de Antropología y Ética en la Filosofía Patrística y Medieval (203-223). Rosario: Paideia.

" Bertelloni, F. (2011). Natura multipliciter dicitur. Variantes en el uso del concepto de natura en la teoría política medieval a partir de la segunda mitad del siglo XIII. Scripta Mediaevalia, 4 (2), pp. 11-29.

" Bertelloni, F. (2012). La filosofía explica la revelación. Sobre el "averroismo político" en el Defensor Pacis de Marsilio de Padua. Patristica et Mediaevalia, XXXIII, 17-36.

》Bianchi, L. (1994). Filosofi, Uomini e Bruti. Note per la Storia di un'Antropologia "Averroista". Rivista da Faculdade de Ciencias Sociais e Humanas, 105-126.

» Busnelli, G. (1921). La cosmogonia dantesca e le sue fonti. Milán: Vita e Pensiero.

» De Libera, A. (1991). Averroès et l'averroîsme. Paris: Presses Universitaires de France.

»Ercole, F. (1921). Medio Evo e Rinascimento nella dottina política di Dante. Giornale Dantesco, XXIV, 141-167.

》Ercole, F. (1928). Il pensiero político di Dante. Milán: Alpes.

»Imbach, R. (2003). Dante, la philosophie et les laïcs. Turín: Marietti.

»Inglese, G. (Ed.). (2004). Dante Alighieri. Convivio. Milán: BUR.

" Mandonnet, P. (1911). Siger de Brabant et l'averroïsme latina au XIII siècle, I et II. Louvain: Institut supérieur de philosophie.

》 Minecan, A.M. (2010). Introducción al debate historiográfico en torno a la noción de "averroísmo latino". Anales del Seminario de Historia de la Filosofía, 27, 63-85.

" Minio-Paluello, L. (1955). Tre note alla Monarchia. En Medioevo e Rinascimento. Studi in onore di Bruno Nardi (503-524). Florencia: Sansoni Editore.

» Nardi, B. (1912). Sigeri di Brabante nella Divina Commedia e le fonti della filosofía di Dante. Pescia: Spianate.

"Nardi, B. (1938). Note critiche di filosofía dantesca. Florencia: Olschki.

» Nardi, B. (1944). Nel mondo di Dante. Roma: Storia e Letteratura.

» Nardi, B. (1949). Dante e la cultura medievale. Bari: Laterza.

"Nardi, B. (1967). Il concetto dell' Impero nello svolgimento del pensiero dantesco. En Saggi di Filosofia Dantesca (215-275). Florencia: La Nuova Italia. 
" Piccini, G. (Ed.). (1906). Guido Vernani. De reprobatione Monarchiae compositae a Dante Aligherio Florentino. Florencia: Bemporad.

» Ricci, P.G. (Ed.). (1965) Dante Alighieri. De Monarchia. Verona:Mondadori.

»Ubl, K. (2003). Republicanismo y platonismo en la Monarchia de Dante. Patristica et Mediaevalia, XXIV, 39-56.

»Van Steenberghen, F. (1980). Thomas Aquinas and radical Aristotelianism. Washington DC: Catholic University of America Press.

»Vinay, G. (1962). Interpretazione della "Monarchia" di Dante. Florencia: Le Monnier. 